\title{
Geotechnical Indications and Shallow Bearing Capacity Analysis within Lekki Peninsula, Lagos using Direct Shear Analysis
}

\author{
T Warmate ${ }^{1}$ and HO Nwankwoala ${ }^{2 *}$ \\ ${ }^{1}$ Geostrat International Services Limited, Nigeria \\ ${ }^{2}$ Department of Geology, Nigeria
}

*Corresponding author: HO Nwankwoala, Department of Geology, Faculty of Science, University of Port Harcourt, Nigeria.
Received Date: January 03, 2019

Published Date: February 14, 2019

\begin{abstract}
It has become imperative for a review of the subsurface engineering properties of the Lekki Peninsula due to increase in urbanization. The study focuses on the shear strength parameters and ultimately the shallow bearing capacity of the subsoil using the direct shear method. With methods based on CPT, SPT, Particle Size Distribution and Direct Shear Analysis, an underlying loosed sandy layer of about $4 \mathrm{~m}$ thick overlying a medium dense sand was revealed. Plot from direct shear analysis reveals zero cohesion and phi values $=170$ indicative of a loosed soil. This loosed property of the soil was also revealed by the non-peaked plot of the direct shear test and the particle size distribution plot. Based on correlation for non-cohesive soils using N-values, compressibility parameters for the loosed sandy layer ( $\mathrm{N}$ values=5) indicates Elastic Modulus < $3500 \mathrm{Kpa}$, while the Medium dense sandy layer ( $\mathrm{N}$ values=17) indicates values of about $13000 \mathrm{Kpa}$. This implies high compressibility is expected within the loosed sandy layer. Settlement predictions based on a loading of $200 \mathrm{KN} / \mathrm{m}^{2}$ indicated a settlement of $74 \mathrm{~mm}$. Recorded Water level is less than $1 \mathrm{~m}$. Based on a shallow bearing capacity of 55kpa and intolerable settlements and CPT values within the study area, a raft foundation is most appropriate for multistory building while a deep foundation is apt for higher loads.
\end{abstract}

Keywords: Subsoil; Geotechnical; Bearing capacity; Foundation; Design; Lekki penninsula; Lagos

\section{Introduction}

Geotechnical site investigation is the process of collecting information and evaluating the conditions of the site for the purpose of designing and constructing the foundation for a structure, such as a building, plant or bridge [1,2]. Foundation studies usually provide subsurface information that aid in the design of structures $[3,4]$. Good planning for and management of a geotechnical site investigation is the key to obtaining sufficient and correct site information for designing a structure in a timely manner and with minimum cost for the effort needed [5,6]. The effort and detail of the geotechnical site investigation to obtain sufficient and correct site information to select and design a foundation for a building is complex [7]. It depends on the following: (a) design criteria of the proposed structure; (b) historic knowledge of general site conditions and building performance; (c) drilling equipment availability; (d) time of year the work needs to be done may determine the geotechnical site investigation method and finally; (e) the overall costs. With the increasing population growth in Lagos State, Nigeria, development activities have been on the rise around the coastal areas of the state. One of such cities is the Lekki Peninsula. The area of the city is about $800 \mathrm{~km}^{2}$ with a Population greater than 400,000 (Wikipedia). The review of the Subsoil is penitent in view of the high rate of urbanization within the area. This Study is to review the stratigraphy of the superficial deposit underlying the area to a depth of $10 \mathrm{~m}$, to determine relevant engineering characteristics of the deposits, to enable appropriate foundation design of the structure and ultimately estimates its Shear Strength parameters/ shallow bearing capacity using the Direct Shear method. [8,9] states that the shear strength parameters (angle of internal Friction and cohesion) is the principal engineering property that determines 
the stability of soils under structural load. Investigative procedures comprise of one (1No.) boring and two Cone Penetrometer.

\section{Site Description and Geology}

Lagos metropolis is located within the Western Nigeria Coastal Zone, a zone of coastal creeks and lagoons [10] developed by barrier beaches associated with sand deposition [11]. The surface geology is made up of the Benin Formation (Miocene to Recent) and the Recent littoral alluvial deposits. The Benin formation consists of thick bodies of yellowish (ferruginous) and white sands [12]. It is friable, poorly sorted with intercalation of shale, clay lenses and sandy clay with lignite. The formation attains a thickness of about $200 \mathrm{~m}$ elsewhere [13] (Figure 1).

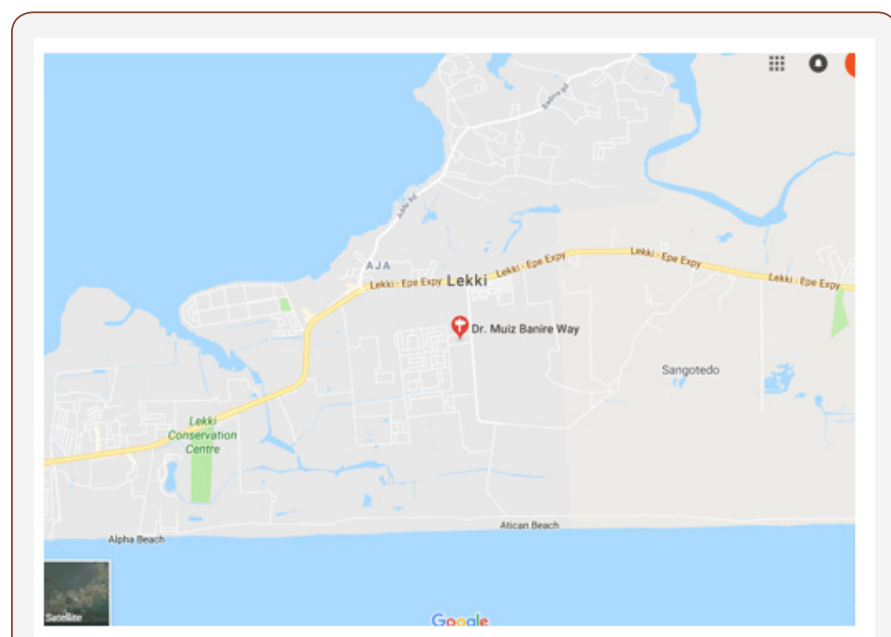

Figure 1: Site Location

\section{Methods of Investigation}

\section{Soil borings}

Conventional boring method which consists of the use of the light shell and auger hand rig was used in the boring operation. During the boring operations, disturbed samples were regularly collected at depths of $0.75 \mathrm{~m}$ intervals and also when change of soil type is noticed. Undisturbed cohesive soil samples will be retrieved from the boreholes with conventional open-tube sampler $100 \mathrm{~mm}$ in diameter and $450 \mathrm{~mm}$ in length. The open-tube sampler consists essentially of a lower end and upper end screwed into a drive head which is attached to the rods of the rig. The head has an overdrive space and incorporates a non-return valve to permit the escape of air or water as the samples enters the tube. The sampler is driven into the soil by dynamic means using a drop hammer. On withdrawal of the sampler, the non-return valve assists in retaining the sample in the tube. All samples recovered from the boreholes were examined, identified and roughly classified in the field. Standard Penetration Tests (SPT) was performed every $1.5 \mathrm{~m}$ advance through cohesionless soils. The main objective of this test is to assess the relative densities of the cohesionless soils penetrated. In this test, a $50 \mathrm{~mm}$ diameter split spoon sampler is driven $450 \mathrm{~mm}$ into the soil with a $63.5 \mathrm{~kg}$ hammer falling freely a distance of $760 \mathrm{~mm}$. The sampler is driven into the soil in two stages. The initial $150 \mathrm{~mm}$ penetration of the sampler is the seating drive and the last $300 \mathrm{~mm}$ penetration, the test drive. The number of blows required to affect the last $300 \mathrm{~mm}$ penetration below the seating drive provide an indication of the relative density of the cohesionless soil stratum tested. This is also referred to as the $\mathrm{N}$-value. The penetration resistance in blow counts with depth are indicated on the borehole logs.

\section{Cone penetration testing}

Hydraulically operated, GMF type, static penetrometer of $100 \mathrm{KN}$ capacity was used in the cone resistance soundings. Mechanical mantle cone with friction jacket was used in the operation. Discontinuous sounding procedure was adopted in the test. The cone in its retracted position is first forced into the ground a distance of $10 \mathrm{~cm}$ by the application of force to the outer sounding tubes. The cone is then pushed out a distance of about $4 \mathrm{~cm}$ by the application of force to the inner rods only and the magnitude of the force required to achieve this, is measured on the pressure gauges and recorded. This is the cone resistance based on ASTM 3441.

\section{Direct shear test}

This test which is the oldest form of Strength Tests, was first used by coulomb in 1976 [14]. It determines the consolidationdrained Shear Strength of sandy to silty soil. The soil is held in a box that splits across its middle. A confining normal force is applied and then a shear force is applied to cause relative displacement. The functional relationship between normal stress and shear stress on a failure plane can be expressed in the following form $[15,16]$. Though the failure occurs at a designated plane which might not be the weakest plane, it is a quick way of determining the strength parameters. BS 1377, Part 7, describes method of test for determining shear strength parameters of soils.

$$
\tau=\mathrm{f}(\sigma)
$$

Where;

$\tau=$ shear stress

$\sigma=$ normal stress

From the test, the shear strength, which is a measure of the resistance to shear stress can be deduced from the equation below

$$
\tau=c+\sigma \tan
$$

$\tau=$ shear strength

$\mathrm{c}=$ cohesion

$\emptyset=$ angle of internal friction

The Theory implies that the failure occurs due to the combination of the normal and shear stress.

\section{Result}

\section{Soil stratigraphy}

The data from the soil sampling, standard penetration tests, and laboratory tests were carefully evaluated for the determination of the stratification of the underlying soils. The evaluation uncovered a primary soil zones beneath the site.

A typical soil profile characterizing the site is described below.

(i) Loosed sandy layer $(0-4 \mathrm{~m})$ 
(ii) Medium Dense Sandy Layer (4-10m)

The stratigraphy beneath the site showed significant uniformity. The ranges of thicknesses of the different strata are shown below (Table 1) (Figure 2).

Table 1: Strata Thicknesses.

\begin{tabular}{|c|c|c|}
\hline Description of Stratum & Min & Max \\
\hline & 4 & - \\
\hline $\begin{array}{c}\text { Loosed sandy layer } \\
\text { Medium Dense Sandy } \\
\text { Layer }\end{array}$ & 6 & - \\
\hline
\end{tabular}

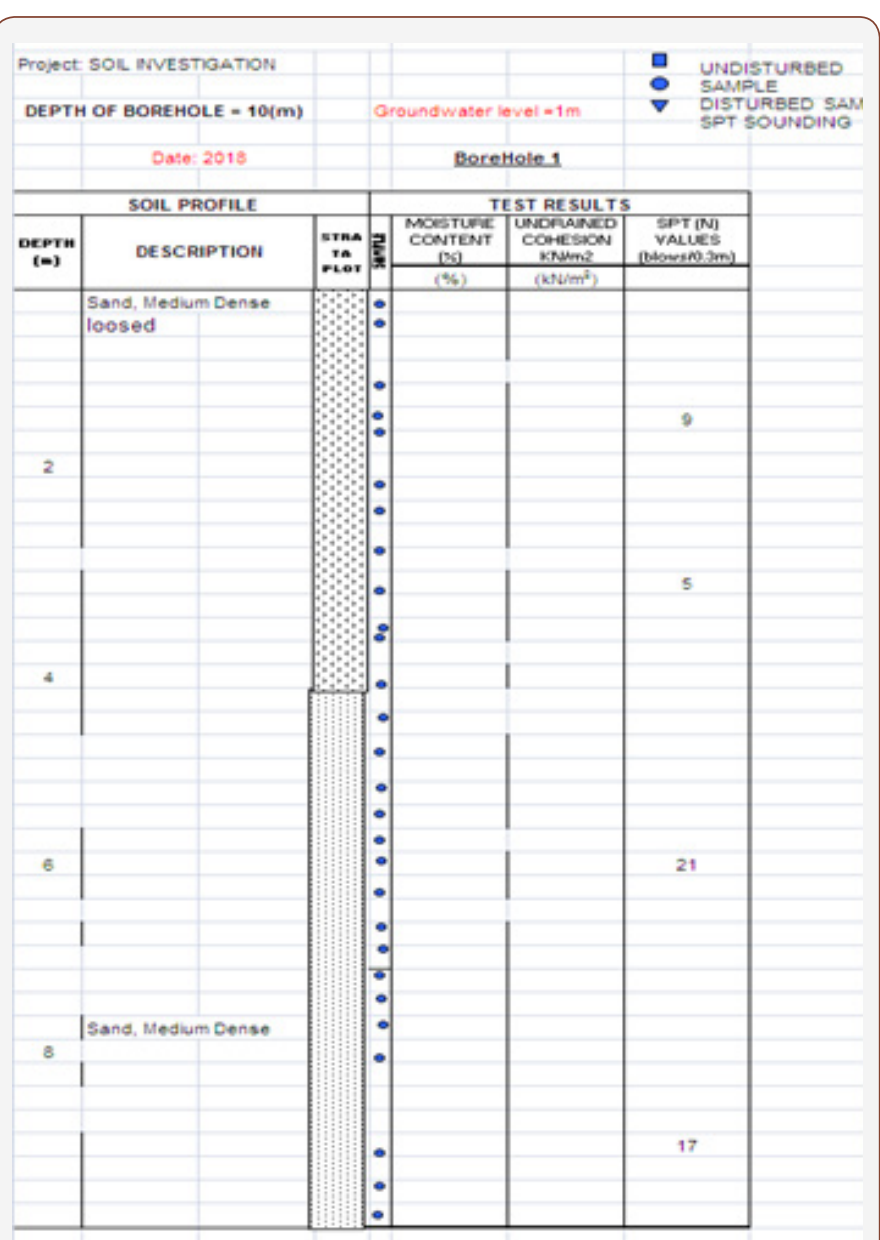

Figure 2: Lithology for $\mathrm{BH} 1$.

\section{Engineering properties of the soils}

The investigation disclosed that the soil deposits within the depths explored are characterized by a near-surface deposit of loosed Sandy layer. Beneath is a Medium Dense Sandy layer. The thickness of the most compressible zone is roughly $0 \mathrm{~m}$. The water table was encountered at $1 \mathrm{~m}$. Classification, strength and compressibility characteristics of the soils were determined from the laboratory and in-situ tests. The relevant index and engineering parameters of the soils are summarized below. Details of these are presented in tables at the end of this report.

\section{Loosed sandy layer}

Underlying the surface is a layer of predominantly poorly sorted, loosed sand. About $4 \mathrm{~m}$ of the sand deposit was proved. The ranges of variations in the relevant engineering parameters of the sand are given below:-(Table 2)

Table 2: Ranges of variation of engineering parameters @3m.

\begin{tabular}{|c|c|}
\hline & Average (BH1, 3m ) \\
\hline Effective particle size $\mathrm{d} 10(\mathrm{~mm})$ & 0.23 \\
\hline Mean particle size $\mathrm{d} 50(\mathrm{~mm})$ & 0.5 \\
\hline Coefficient of uniformity $\mathrm{Cu}=$ & 2.3 \\
\hline Coefficient of curvature $\mathrm{Cc}=$ & 1.1 \\
\hline SPT (N-value) & 5 \\
\hline Elastic Modulus ((Kpa) & 3830 \\
\hline
\end{tabular}

For design purposes, mean angle of internal friction of $<28^{\circ}$ and cohesion zero are suggested for the sand layer. Unit weight of $20 \mathrm{kN} / \mathrm{m}^{3}$ are suggested for this layer

\section{Medium dense sandy layer}

Underlying the loosed layer is a layer of predominantly Poorly sorted, Medium densed sand. About $6 \mathrm{~m}$ of the sand deposit was proved. The ranges of variations in the relevant engineering parameters of the sand are given below:-(Table 3)

Table 3: Ranges of variations of engineering parameters @9m.

\begin{tabular}{|c|c|}
\hline & Average (BH1, 9m ) \\
\hline Effective particle size $\mathrm{d} 10(\mathrm{~mm})$ & 0.16 \\
\hline Mean particle size d50 $(\mathrm{mm})$ & 0.25 \\
\hline Coefficient of uniformity, Cu & 3.4 \\
\hline Coefficient of curvature, Cc & 0.45 \\
\hline SPT (N-value) & 17 \\
\hline Elastic Modulus ((Kpa) & 13022 \\
\hline
\end{tabular}

For design purposes, mean angle of internal friction of $31^{\circ}$ and cohesion zero are suggested for the sand layer. Unit weight of $20 \mathrm{kN} / \mathrm{m}^{3}$ are suggested for this layer.

\section{Particle size analysis}

Sieve analysis were carried out to determine grain size distribution based on relevant standards. Result from Coefficient of Uniformity and Coefficient of curvature indicates a Poorly sorted soil, hence higher in porosity than well graded soil. Though Muawia [17], stated the impact of clay on the frictional angle, the impact is expected to be insignificant due the quantity of clay which is less than 5\% (Table 4) (Figures 3-5).

Table 4: Particle Size Distribution.

\begin{tabular}{|c|c|c|c|c|c|c|c|}
\hline Borehole No & Depth(m) & $\begin{array}{c}\text { Effective } \\
\text { particle }\end{array}$ & $\mathbf{d 3 0}$ & $\begin{array}{c}\text { Mean particle } \\
\text { size d50(mm) }\end{array}$ & $\mathbf{d 6 0}$ & $\begin{array}{c}\text { Coefficient of } \\
\text { uniformity }\end{array}$ & $\begin{array}{c}\text { Coefficient of } \\
\text { curvature }\end{array}$ \\
\hline 1 & 3 & 0.25 & 0.38 & 0.5 & 0.59 & 2.36 & 0.97 \\
\hline 1 & 9 & 0.16 & 0.2 & 0.25 & 0.55 & 3.4375 & 0.4545455 \\
\hline
\end{tabular}


Particle Size Distribution for BH1, 3m, Lekki

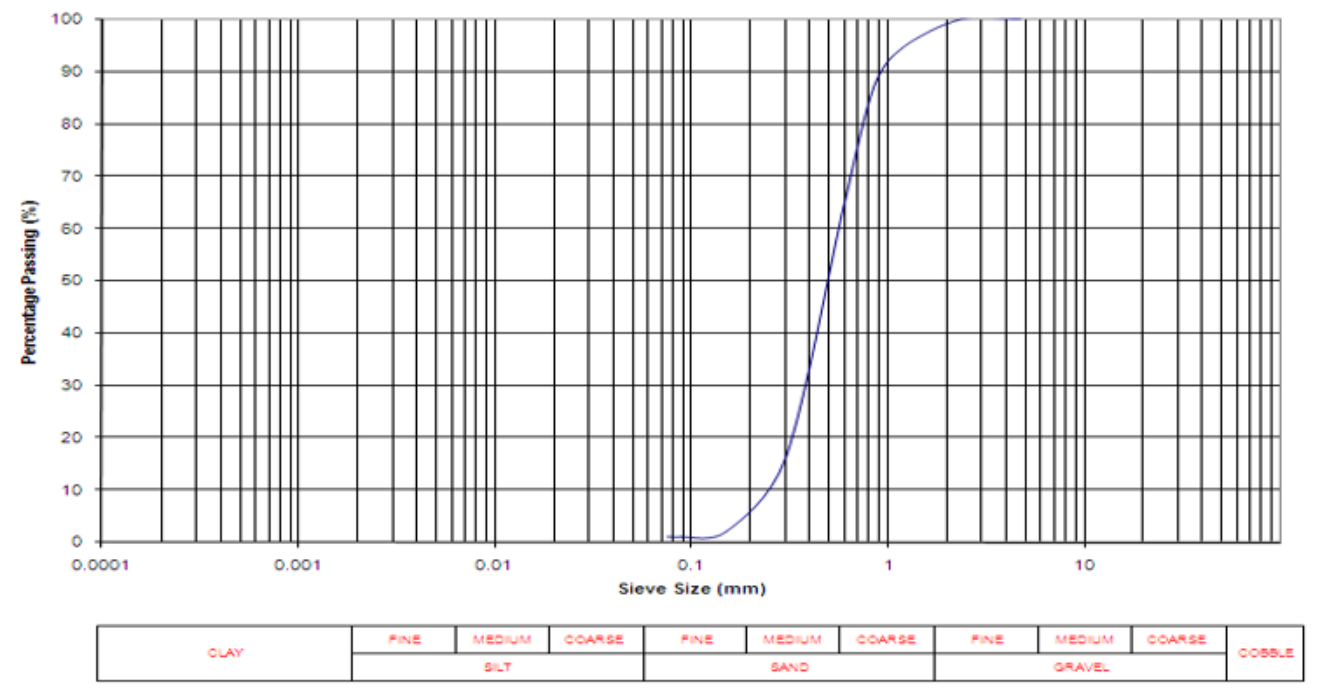

Figure 3: Particle Size Distribution at depth of 3m.

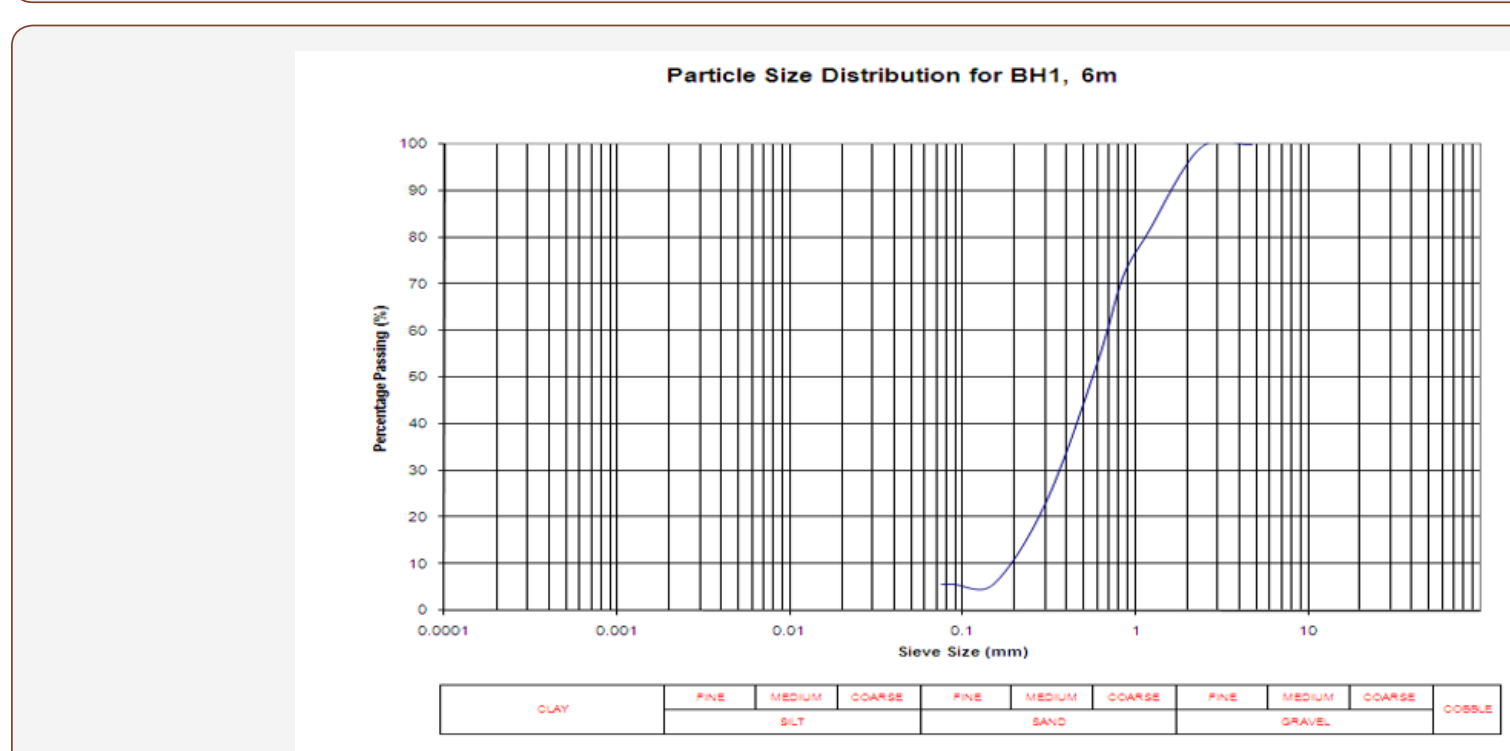

Figure 4: Particle Size Distribution at depth of $6 \mathrm{~m}$.

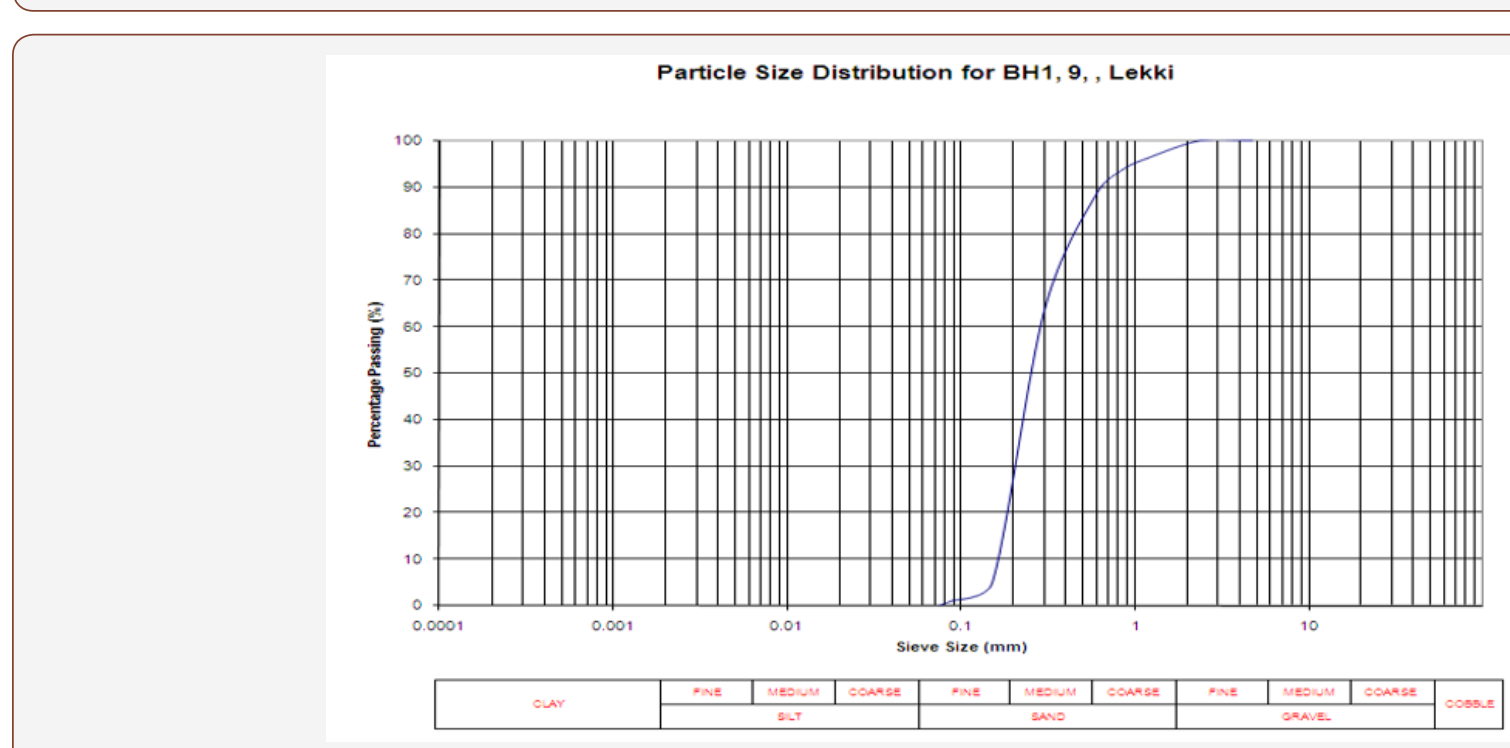

Figure 5: Particle Size Distribution at depth of $9 \mathrm{~m}$. 


\section{Direct shear analysis}

Due to the non - cohesiveness of the retrieved samples at shallow depths, Direct shear analysis was carried out based on methods from BS 1377, Part 7 (Direct Shear) ASTM D 3080. Constant confined normal stress of $50 \mathrm{KN} / \mathrm{m}^{2}$ and $100 \mathrm{KN} / \mathrm{m}^{2}$ shows variation of shear stress and shear displacement using a shearing rate of $0.24 \mathrm{~mm} /$ minute. Plot of Normal stress and Shear stress indicates an angle of friction of 150. Curves from the Stress / Strain Plot indicates a loosed sand, as indicated by the non-peaked curve; thus, a low bearing capacity is expected. This fact is also corroborated by the Particle Distribution Curve. The Linear curve from the Normal /Shear Stress Plot that passes through the origin also depicts a cohesionless soil with zero cohesion.; this implies the soil will not stand as a cylinder if the confining pressure is zero. Hence, making the failure law to be simplified as follows: $\tau=\sigma \tan \varphi$

(Table 5) (Figures 6,7)

Table 5: Direct Shear Tests.

\begin{tabular}{|c|c|c|c|c|}
\hline \multirow{3}{*}{$\begin{array}{c}\text { Bore-Hole } \\
\text { No }\end{array}$} & $\begin{array}{l}\text { Depth } \\
\text { Sample }\end{array}$ & Normal & \multirow{3}{*}{50} & \multirow{3}{*}{100} \\
\hline & (m) & Stress & & \\
\hline & & $\mathrm{KN} / \mathrm{m}^{2}$ & & \\
\hline \multirow[t]{2}{*}{1} & 1.5 & Shear Stress & \multirow{2}{*}{12} & \multirow{2}{*}{20} \\
\hline & & $\mathrm{KN} / \mathrm{m}^{2}$ & & \\
\hline & & Phi & \multicolumn{2}{|c|}{170} \\
\hline & & $\begin{array}{c}\text { Saturated unit } \\
\text { weight }\end{array}$ & \multicolumn{2}{|c|}{18.5} \\
\hline & & Specific Gravity & \multicolumn{2}{|c|}{2.65} \\
\hline
\end{tabular}

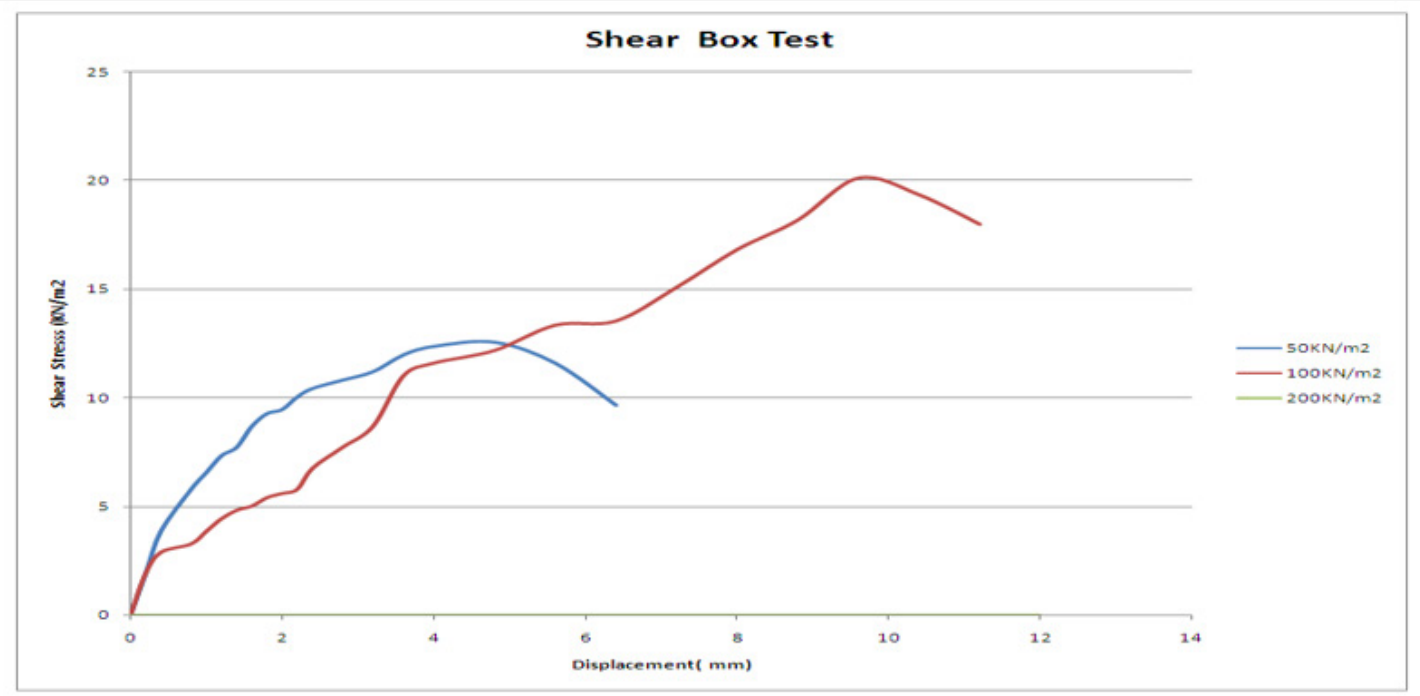

Figure 6: Variation of Displacement to Shear Stress.

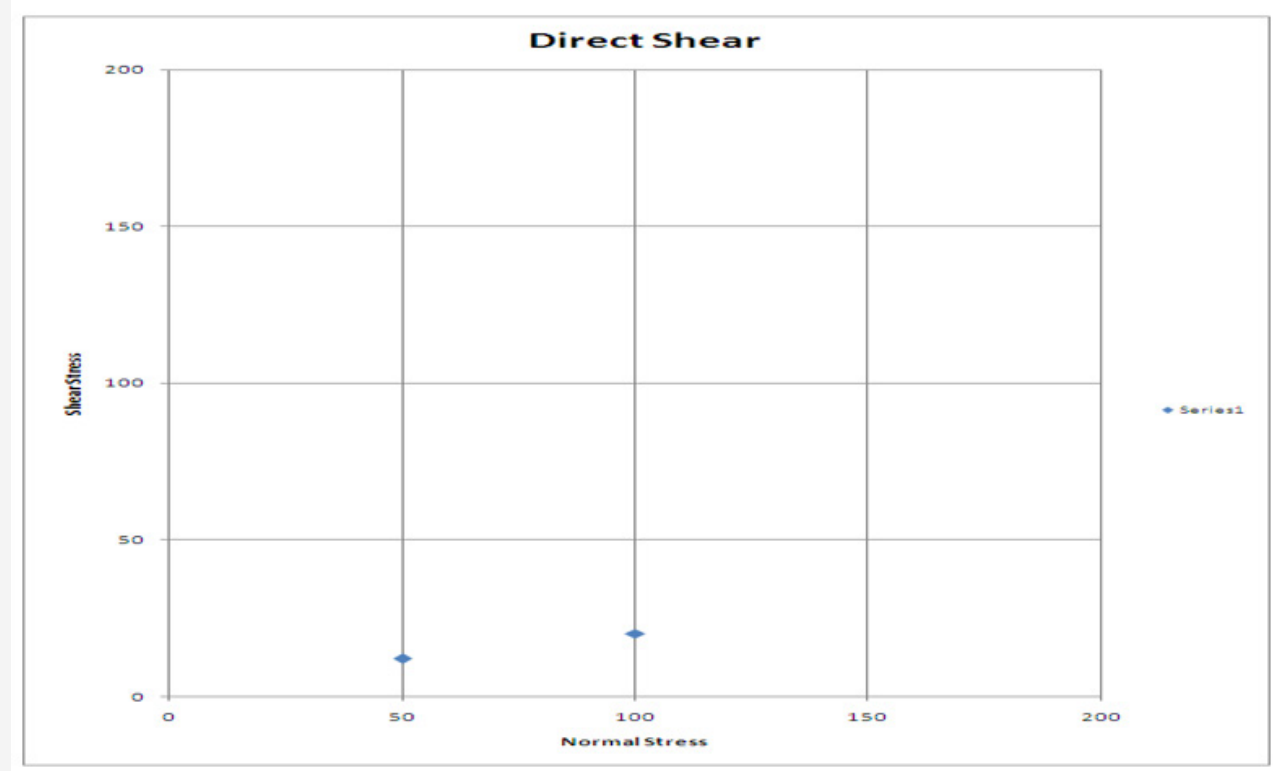

Figure 7: Variation of Normal and Shear stress. 


\section{Cone penetrometer results}

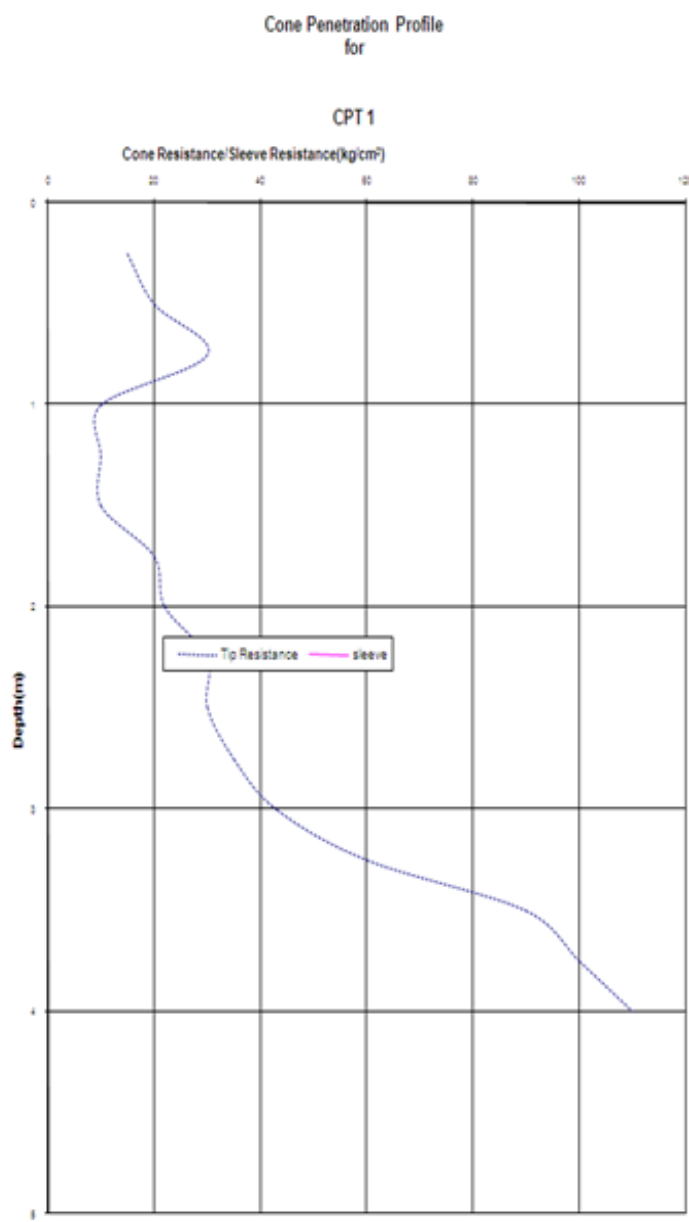

Figure 8: CPT Profile 1.

Cone Penetrometer Profiles were carried out within the area to a depth of less than $6 \mathrm{~m}$. Analysis of the tip resistance values indicates, values less than $60 \mathrm{~kg} / \mathrm{cm}^{2}$ at depth less than $3.5 \mathrm{~m}$, while values greater than $60 \mathrm{~kg} / \mathrm{cm}^{2}$ were observed at depth greater than $3.5 \mathrm{~m}$. An average depth of $10 \mathrm{~kg} / \mathrm{cm}^{2}$ was observed within depth of $1-2 \mathrm{~m}$ (Figures 8,9).

Table 6: Allowable Bearing Pressure for Shallow Foundation.

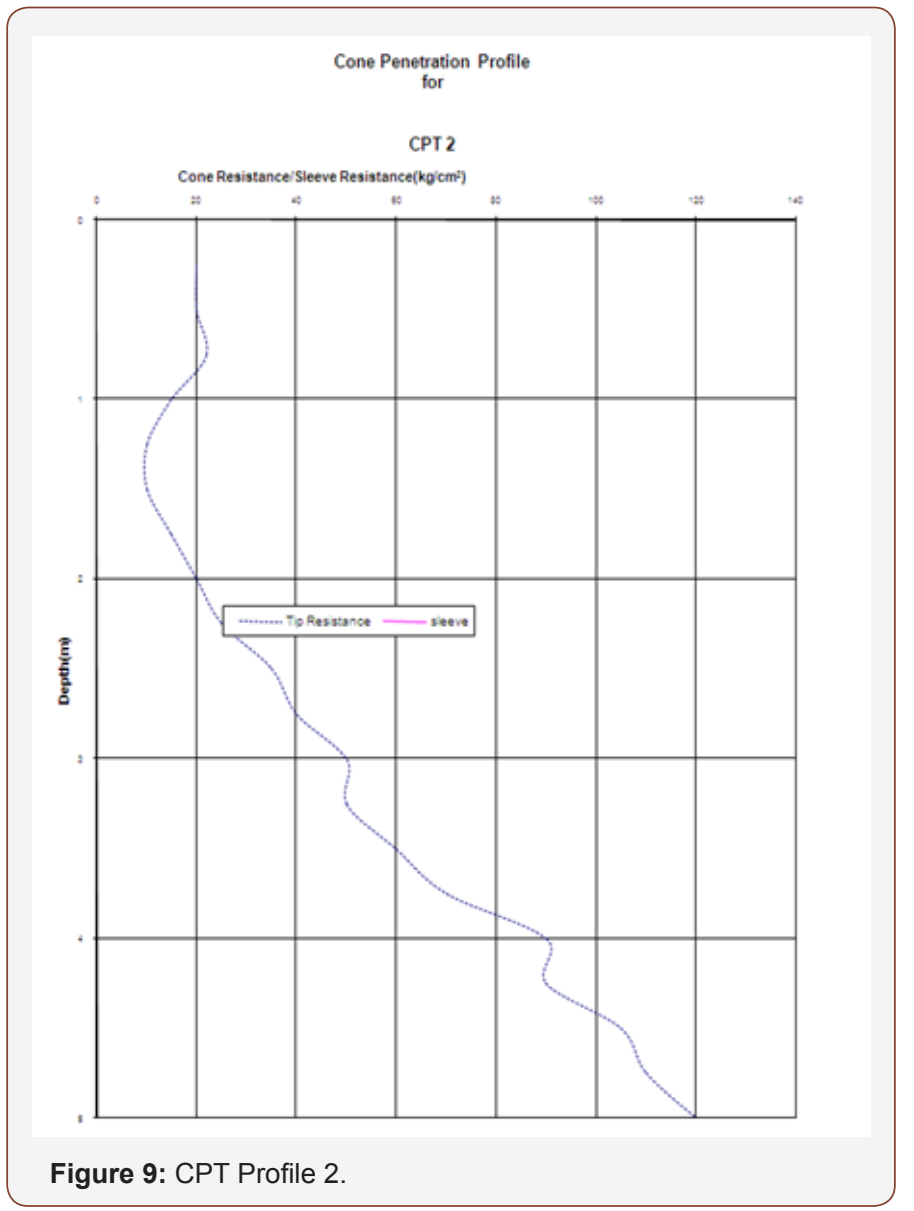

\section{Bearing capacity}

The conventional method of foundation design is based on the concept of bearing capacity or allowable bearing pressure of the soil. The bearing capacity is defined as the load or pressure developed under the foundation without introducing damaging movements in the foundation and in the superstructure supported on the foundation. Damaging movements may result from foundation failure or excessive settlement [18]. The two criteria used in the design of foundation are therefore:

\begin{tabular}{|c|c|c|c|c|c|c|c|c|}
\hline $\begin{array}{c}\text { Foundation } \\
\text { Depth }\end{array}$ & Width & $\begin{array}{c}\text { Undrained } \\
\text { Shear } \\
\text { Strength } \\
\left(\mathrm{KN} / \mathrm{m}^{2}\right)\end{array}$ & \multicolumn{3}{|c|}{ Ultimate Bearing Pressure $\left(\mathrm{KN} / \mathrm{m}^{2}\right)$} & \multicolumn{3}{|c|}{ Allowable Bearing Pressure $\left(\mathrm{KN} / \mathrm{m}^{2}\right)$} \\
\hline & $(\mathrm{m})$ & & $\mathrm{L} / \mathrm{B}=1$ & $\mathrm{~L} / \mathrm{B}=1.5$ & $\mathrm{~L} / \mathrm{B}=5$ & $\mathrm{~L} / \mathrm{B}=1$ & $\mathrm{~L} / \mathrm{B}=1.5$ & $\mathrm{~L} / \mathrm{B}=5$ \\
\hline 1 & 1 & 0 & 118.8 & 121.2 & 124.56 & 39.6 & 40.4 & 41.52 \\
\hline 1 & 1.5 & 0 & 66.6 & 68.4 & 70.92 & 22.2 & 22.8 & 23.64 \\
\hline 1 & 2 & 0 & 73.8 & 76.2 & 79.56 & 24.6 & 25.4 & 26.52 \\
\hline 1 & 2.5 & 0 & 81 & 84 & 88.2 & 27 & 28 & 29.4 \\
\hline 1 & 5 & 0 & 117 & 123 & 131.4 & 39 & 41 & 43.8 \\
\hline 1 & 10 & 0 & 189 & 201 & 217.8 & 63 & 67 & 72.6 \\
\hline 1.5 & 1 & 0 & 163.8 & 166.2 & 169.56 & 54.6 & 55.4 & 56.52 \\
\hline 1.5 & 1.5 & 0 & 89.1 & 90.9 & 93.42 & 29.7 & 30.3 & 31.14 \\
\hline 1.5 & 2 & 0 & 96.3 & 98.7 & 102.06 & 32.1 & 32.9 & 34.02 \\
\hline 1.5 & 2.5 & 0 & 103.5 & 106.5 & 110.7 & 34.5 & 35.5 & 36.9 \\
\hline 1.5 & 5 & 0 & 139.5 & 145.5 & 153.9 & 46.5 & 48.5 & 51.3 \\
\hline
\end{tabular}




\begin{tabular}{|c|c|c|c|c|c|c|c|c|}
\hline 1.5 & 10 & 0 & 211.5 & 223.5 & 240.3 & 70.5 & 74.5 & 80.1 \\
\hline 2 & 1 & 0 & 208.8 & 211.2 & 214.56 & 69.6 & 70.4 & 71.52 \\
\hline 2 & 1.5 & 0 & 111.6 & 113.4 & 115.92 & 37.2 & 37.8 & 38.64 \\
\hline 2 & 2 & 0 & 118.8 & 121.2 & 124.56 & 39.6 & 40.4 & 41.52 \\
\hline 2 & 2.5 & 0 & 126 & 129 & 133.2 & 42 & 43 & 44.4 \\
\hline 2 & 5 & 0 & 162 & 168 & 176.4 & 54 & 56 & 58.8 \\
\hline 2 & 10 & 0 & 234 & 246 & 262.8 & 78 & 82 & 87.6 \\
\hline
\end{tabular}

1. Determination of bearing capacity of soil and the selection of adequate factor of safety, usually not less than $2.5 \mathrm{~cm}$.

2. Estimating the settlement under the expected load and comparison with the permissible settlement.

Modified Terzerghi Bearing Capacity equation [19] was used in the calculation of the ultimate bearing capacity of the soil for rectangular foundations:

$q_{u}=C N_{c}[1+0.3 B L]+\gamma D_{f} N_{q}+12 \gamma B N_{\gamma}[1-0.2 B L]$

Where

$q_{u}=$ ultimate bearing capacity

$N_{c}, N_{q}, N_{\gamma}$ = bearing capacity factors

$D_{f}=$ depth of foundation

$\gamma=$ unit weight

$B=$ width

$L=$ length

Undrained cohesion of $0 \mathrm{kPa}$ and angle of internal friction of 17 were adopted for the bearing capacity analysis. Adopting methods from BS 1377, Part 7 (Direct Shear). Using appropriate bearing capacity factors, shallow bearing capacity is calculated as follows:(Table 6)

\section{Settlement of shallow foundation}

Settlement Analysis was done based on empirical method using Cone Penetrometer values. Tomlinson [20], stated method to calculate the compressibility parameters as follows;

$$
S=C_{1} C_{2} \Delta_{p} \sum_{0}^{2 B} \frac{I_{Z}}{E_{S}} \Delta_{C}
$$

Where

$S=$ settlement

$C_{1}=$ Depth correction factor

$C_{2}=$ creep correction factor

$E_{S}=$ Dedormation modulus

$\Delta_{p}=$ net increase of load on soil at foundation level due to applied load

$\Delta_{C}=$ thickness of soil layer

$I_{Z}=$ influence factor

$B=$ width
Based on relationships settlement estimates of $74 \mathrm{~mm}$ can be expected for a projected load of $200 \mathrm{KPa}$.

(Table 7) (Figure 10)

Table 7: Settlements Parameters.

\begin{tabular}{|c|c|}
\hline Sandy, $1.5 \mathrm{~m}$ & \\
\hline Elastic Modulus, PA & 2450 \\
\hline Cone Value, Kg/cm2 & 10 \\
\hline Load, Kpa & 200 \\
\hline Influence Factor & 0.5 \\
\hline Pi (elastic), mm & 74 \\
\hline Pc (Primary), mm & \\
\hline
\end{tabular}

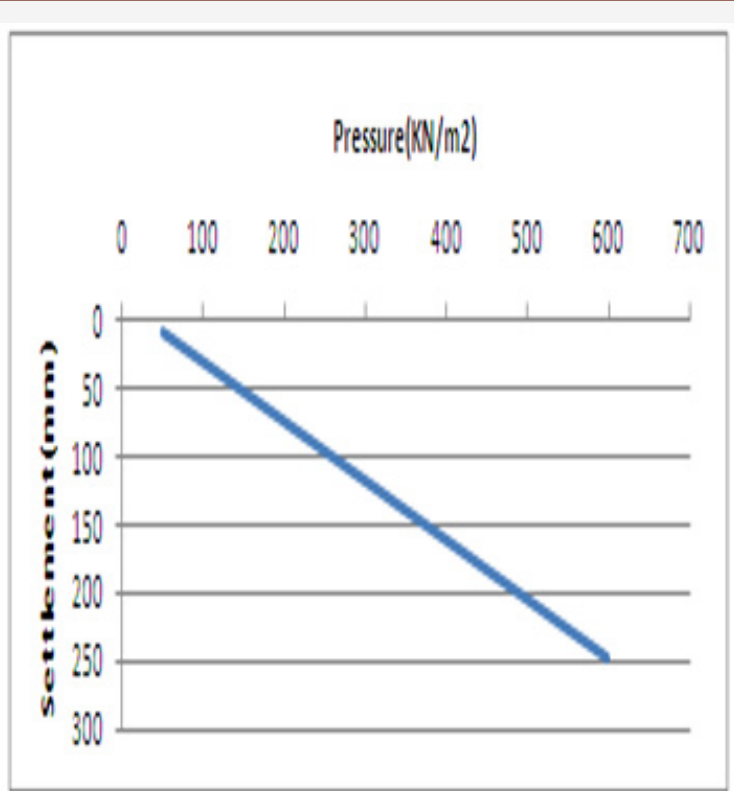

Figure 10: Variation of Settlement with foundation pressure.

\section{Discussion}

Field and Laboratory investigations shows that the surface is underlain by a Poorly loosed sandy layer (about $4 \mathrm{~m}$ thick) with $\mathrm{N}$-values $<10$. The uniformity coefficient of the Particle size distribution curve, indicates values less than 6, depicting a loosed sand. This value is also corroborated by values of Coefficient of curvature which indicates less than 1.0 [21]. Also, the loosed layer is corroborated by Cone penetrometer values (Tip Resistance $<60 \mathrm{~kg} /$ $\mathrm{cm}^{2}$ ). The medium dense layer is correlated by Cone Penetrometer values (Tip Resistance> $\mathrm{kg} / \mathrm{cm}^{2}$ ). Average Cone Penetrometer values (Tip Resistance) indicates lower values of about $10 \mathrm{~kg} / \mathrm{cm}^{2}$ within depth of $1 \mathrm{~m}-2 \mathrm{~m}$. This implies a weak zone that is highly susceptible to shear failure. Using allowable bearing capacity equation proposed by Schmertmann [22] based on CPT values 
and considering the effect of water table, shows allowable bearing capacity of 58kpa (FS=3, square foundation) using a cone value of $10 \mathrm{~kg} / \mathrm{cm}^{2}$.

Results derived from shear stress/ displacement plot were plotted with the Normal stress, Phi value of 170 and zero cohesion were obtained from the test. Application of these values in relevant bearing capacity equation above gave rise to low allowable bearing Capacities characteristics (1.5m: $\left.55 \mathrm{KN} / \mathrm{m}^{2}\right)$. This value also correlates with the allowable bearing capacity values obtained from Cone Penetrometer values using schmertmann method

Based on correlation stated by Das [21] for non-cohesive soils using $\mathrm{N}$-values, Compressibility Parameters for the loosed sandy layer ( $\mathrm{N}$ value $=5$ ) indicates Elastic Modulus < 3500Kpa, while the Medium dense sandy layer ( $\mathrm{N}$ value=17) indicates values of about $13000 \mathrm{Kp}$. This implies high compressibility is expected within the loosed sandy layer based on correlation stated by Tomlinson [20]. Settlement predictions based on a loading of $200 \mathrm{KN} / \mathrm{m} 2$ indicated a settlement of $74 \mathrm{~mm}$. Recorded Water level is less than $1 \mathrm{~m}$.

\section{Conclusion}

Based on the loosed nature of the sandy soil from the Particle Size Distribution, anticipated high settlement and low shallow bearing capacity of $55 \mathrm{kpa}$ at depth of $1.5 \mathrm{~m}$ within the study area of the lekki peninsula with an intolerable settlement, raft foundation on a compacted layer is most appropriate for shallow foundation with foundation (footing) stress not greater 55kpa. For higher loads, a deep foundation will be most appropriate with founding depth > $5 \mathrm{~m}$. The study recommended that continuous foundation footings should not be placed on the identified clay soil unit. It should also be noted that foundations of large civil engineering structures in the area should be safely anchored in form of piles on competent sand materials for sustainability.

\section{Acknowledgment}

None.

\section{Conflict of Interest}

No conflict of interest.

\section{References}

1. Nwankwoala HO, Warmate T (2014) Subsurface Soil Characterization of a Site for Infrastructural Development Purposes in D/Line, Port Harcourt, Nigeria. American International Journal of Contemporary Research, 4(6): 139-148.

2. Nwankwoala HO, Amadi AN, Warmate T, Jimoh MO (2015) Geotechnical Properties of Sub- Soils in Escravos Estuary, Western Niger Delta,
Nigeria. American Journal of Civil Engineering and Architecture, 3(1):814.

3. Adepelumi AA, Olorunfemi MO (2000) Engineering geological and geophysical Investigation of the reclaimed Lekki peninsula, Lagos, Southwestern, Nigeria. Bull. Eng. and Env, 58 (2): 125-131.

4. Adepelumi AA, Olorunfemi MO, Falebita DE, Bayowa OG (2009) Structural mapping of coastal plain sands using engineering geophysical technique: Lagos Nigeria case study, Natural Science, 1(1): 2-9.

5. Braja M Das (2005) Fundamentals of geotechnical Engineering. 2nd Ed., Quebecor Printers.

6. CGS (2006) Canadian Foundation Manual, 4th Edition. The Canadian Geotechnical Society c/o BiTech Publisher Ltd.

7. Bolton MD (1981) Limit State Design in geotechnical Engineering, Ground Engineering, 14 (6): 39-46.

8. Bjerrum L, Eggestad A (1963) Interpretation of Loading Tests on Sand, Proc. Eur. Conf. Soil Mech. \& Found. Eng., 1: p.199.

9. Neringa D, Šarūnas S, Andrius G (2017) Experimental and Numerical Analysis of Direct Shear Test. Science Direct, 172:218-225.

10. Pugh JC (1954) A classification of the Nigerian coastline. JW AfrSci 1: 3-12.

11. Hill MB, Webb JE (1958) The topography and physical features of Lagos Harbour. Phil. Trans R. Soc. (Series B) 241: 319-333.

12. Jones HA, Hockey RD (1964) The geology of part of South-Western Nigeria. Geol. Surv. Nig. Bull. 31.

13. Short KC, Stauble AJ (1969) Outline of geology of the Niger Delta. Bull. Am. Ass. Petrol. Geol 54: 761-779.

14. Lambe TW, Whitman RV (1979) Soil Mechanics, SI Version. John Wiley and Sons Inc.

15. Mohr O (1900) Welche Umstände bedingen die Elastizitätsgrenze und den Bruch eines Materials? Zeit des Ver Deut Ing 44:1524-1530.

16. Gopal R, Rao ASR (2000) Basic and Applied Soil Mechanics. Revised 2nd Ed. New Age International Publishers.

17. Muawia AD (2012) Effects of Clay and Moisture Content on Direct Shear Tests for Clay-Sand Mixtures. Advances in Materials Science and Engineering, 10(2): $23-29$.

18. Meyerhof GG (1970) Safety factors \& Limit State Analysis in Geotechnical Engineering, Canadian Geotechnical Journal, 21 (1): 1-7.

19. Murthy VNS (2007) Soil Mechanics and Foundation Engineering. CBS Publishers and Distributors Pvt Ltd, New Delhi.

20. Tomlinson MJ (1999) Foundation Design and Construction 6th Edition, Longman, $536 \mathrm{pp}$.

21. Das BM (1994) Principles of Geotechnical Engineering. PWS Publishing Company, USA.

22. Schmartmann H (1978) Estimating the true consolidation behavior of clay from laboratory test results. Proceedings of the American Society of Civil Engineers 79 Separate No.311. 